Fortescue Flannery dealt with the main points in the different designs of single-acting and doubleacting, and of four-stroke and two-stroke engines such as the Burmeister and Wain, North British, Tosi, Vickers, Werkspoor, Doxford, Fullagar, Polar, and Sulzer, and also of that most interesting development, the Still engine, which is a Diesel engine and steamengine combined. Developments are still proceeding with rapid strides towards the double-acting type and the consequent increase of power in proportion to the weight, but there is at present no approach to the standardisation such as is attained in the tripleexpansion engine.

During the course of the evening, Lord Bearsted read a characteristic letter on the oil question from the late Lord Fisher, written in I9II, and he also gave some figures respecting the oil-engines suitable for a light cruiser. The cruiser, it is true, would have a speed of 26 knots as against a speed of 28 knots of her sister ship with steam machinery, but she would have a very much greater radius of action.
He seemed to think that the Admiralty has not done so much as it might to further the progress of the oil-engine for propulsion.

In the discussion that followed, Engineer Admiral Sir Robert Dixon, the Engineer-in-Chief of the Fleet, recalled the work done in the Navy on the Diesel engines for submarines and referred to the experimental plant founded at West Drayton. Before an oilengined battleship is feasible, however, the Diesel engine must give far more power for its weight than those in existence at present.

It may be remarked that even the late Lord Fisher would scarcely have cared to command a light cruiser of 26 knots, even if fitted with oil-engines, when trying to overtake an enemy ship of the same class wth a speed of 28 knots. In building the famous Dreadnought, a thousand tons in weight and roo,oool. in money were saved by the adoption of steam-turbine machinery, but there seems little prospect at present of doing anything similar by the adoption of Diesel engines in a man-of-war.

\title{
The Effects of Posture and Rest in Muscular Work. ${ }^{1}$
}

THE problems of muscular activity have been investigated for many years from an academic viewpoint, yet it is only in recent times that a demand has arisen for the application of exact means of measurements of the physiological cost of muscular work in industry. The Medical Research Council's report for the years I $923-24$ states that "The studies of muscle function which were almost notorious for their supposed uselessness to the student or physician have laid down basic knowledge which now underlies many parts of medical science and art, and are beginning to remove empiricism from practical studies of physical training and of industrial labour."

The output of energy of an individual may be calculated by measuring the amount of oxygen and carbon dioxide present in the expired air, and from these data the physiological cost of the work can be assessed. This method of estimating the "cost" of work or muscular activity places at our disposal a means of comparing the efficiency and capacity of the human machines under different conditions.

Two methods are available for the measurement of energy output- $-(a)$ direct and $(b)$ indirect calorimetry. The unit of measurement used is the large or kilo calory. In direct calorimetry the individual is enclosed in a special chamber so constructed that the heat given off is measured. The apparatus is also arranged for the collection of the expired air, so that direct and indirect calorimetry may be combined.

In indirect calorimetry the subject wears a mouthpiece fitted with two valves. One valve serves for inspiration, while the other valve allows the expired air to pass down through a wide tube into a rubber bag, which the subject carries during the experiment. The expired air can be drawn off and analysed in a Haldane apparatus. The ratio of carbon dioxide given off to oxygen absorbed can then be obtained, and from these data the heat units are calculated. If the measurements are carried out on the subject at rest and during work, an exact estimation can be made of the energy required for this particular task.

In a recent publication of the Industrial Fatigue Research Board on "The Effects of Posture and Rest in Muscular Work," Miss E. M. Bedale has investigated

1 Medical Research Council: Industrial Fatigue Research Board. Report No. 29: "The Effects of Posture and Rest in Muscular Work: (a) Comparison of the Energy Expenditure of a Woman carrying Loads in Eight Different Positions," by E. M. Bedale; $(b)$ "The Influence of Rest Pauses and Changes of Posture on the Capacity for Muscular Work," by Dr. H. M. Vernon. Pp. 55. (London: H.M. Stationery Office, I924.) 2s. 6d. net.

NO. 2887 , VOL. I I 5$]$ the energy expenditure of a woman carrying loads in different positions. Miss Bedale has used the indirect calorimetric method for estimating the physiological costs of the work. It is shown from the measurements made that the energy expenditure varies with the position in which the load is carried. The physiological cost of carrying with a yoke is low and involves less physiological disturbance than any other. The experiments suggest that the continuous carrying of a load exceeding 35 per cent. of the body-weight is likely to cause rapid impairment of working capacity. A series of photographs of the different modes of weight-carrying bring out the importance of the study of body posture. Some of the methods, if used continually, will rapidly lead to body deformities, with impairment of the normal physiological functions. The use in industries of methods least injurious to the body would be an aid in the prevention of disease, and undoubtedly lead to greater efficiency. The results of further investigations will be awaited with interest. The data collected will tend to remove empiricism from studies of industrial labour, and will give a standard of measurement more accurate than that of output.

Prof. E. P. Cathcart contributes a preface which deals in a clear and concise manner with methods of measurement, and points out the pitfalls which beset the investigator in work of this type.

In the same publication, Dr. H. M. Vernon gives the results of an investigation on "The Influences of Rest Pauses and Changes of Posture in the Capacity for Muscular Work." The conclusions drawn by Dr. Vernon suggest that the promotion of circulation plays an important part in the prevention of fatigue, the value of a rest pause being increased if the worker moves about during the interval. Postural changes during work are shown to be as necessary as rest pauses if efficient work is to be carried out.

An interesting point is raised concerning the effect of additional movements during muscular work. The application of motion study to industrial processes has resulted in the elimination of many unnecessary movements and a marked increase in output. The results now obtained suggest that the removal of too many unnecessary movements may be too drastic, and even better results might be obtained if a few extra movements, sufficient to promote circulation, were allowed. The proof of this suggestion will probably only be obtained by investigating each process separately by the old method of trial and error. 